\title{
Socio-economic inequalities in health in Catalonia
}

\author{
by \\ Pilar García Gómeza and Ángel López Nicolása*
}

March 2004

a D epartament d'Economia i Empresa and CRES, Universitat Pompeu Fabra, 08005-Barcelona, Spain

\begin{abstract}
In this paper we measure the degree of income related inequality in mental health as measured by the GHQ instrument and general health as measured by the EQ OL-5D instrument for the Catalan population. We find that income is the main contributor to inequality, although the share of inequality in mental health that can be explained by income is much greater than the corresponding share of inequality in general health. We also find that the variation in demographic structure reduces income related inequality in mental health and in general health. The regional variations in both instruments for health are striking, with the Barcelona districts faring relatively bad with respect to the rest of geographical areas and Lleida being the health region where, all else held equal, the population reports the greatest level of health. A big share of inequality in the two health measures, but specially mental health, is due to the favourable position in both health and income of those who enjoy an indefinite contract with respect to the rest of individuals. We also find that risky working conditions affect both health measures and are able to explain an important share of socio-economic inequality.
\end{abstract}

JEL classification: D 63, I12, C21

Keywords: Health inequalities; decomposition analysis; mental health; Spain.

* Corresponding author. Tel. +34 93 5422504. Fax: +34 93 5421746. E-mail: angel.lopez@ upf.edu. This paper derives from the project "La dinámica del estado de salud y los factores socieconómicos a lo largo del ciclo vital. Implicaciones para las políticas públicas", which is supported by the Fundación BBVA. We are grateful to Salvi Juncà for providing the data set and to Guillem López for his useful comments and suggestions. The views expressed in this paper are those of the authors and not necessarilythose of the funders or the authors' employers. 


\section{Introduction}

In this paper we measure the degree of income related health inequalities in Catalonia using two distinct health instruments: the GHQ instrument for mental health and the Euroqol-5D instrument for general health. These measures are obtained from the latest representative survey for the Catalan population, the Enquesta de Salut de Catalunya [1], along with a wide set of demographic and socio-economic covariates which we use for modeling health. The study of Catalonia is motivated by the fact that, as early as 1981, this is the first region which gained responsibilities for health care in Spain. Also, Catalonia one of the regions with the highest percentages of i) contracting out to private providers of publicly financed health care and ii) double medical insurance coverage. A recent paper [2] evaluates the degree of income related inequalities in self assessed health and Catalonia ranks high in terms of inequality. With the analysis in this paper we attempt to explore further the socioeconomic correlates of health as measured by alternative instruments in a survey which is representative not only at the regional level but also at the more disaggregated "health region" level and Barcelona city district level.

This paper adds to existing literature on socio-economic health inequalities in Catalonia [3] by using individual, rather than aggregate, data and adopting a multivariate approach. That is, by controlling for as many socio-economic correlates of health, the results are able to provide an accurate picture of the relative contributions of income, activity status, region of residence etc. to the degree of health inequality. Moreover, controlling for confounding factors permits getting close to the "causal" effect of income. While the results presented in this paper cannot be given such causal interpretation at this stage, they go a step beyond the correlations well documented elsewhere in the literature.

Section 2 presents the methodology that we adopt for the measurement and modeling of health and the measurement of socio-economic health inequality. Section 3 briefly comments the data set used throughout the analysis. Section 4 presents the empirical results and section 5 concludes. 


\section{Methods}

\subsection{Measurement of health}

In this paper we use two measures of health: the Euroqol-5D and the GHQ measure for mental health. These instruments map a vector of health indicators to a single index by means of adding the individual indicators according to a set of prescribed social values (weights).

The ESCAT 2002 questionnaire incorporates a reduced version of the $G$ eneral Household Questionnaire [4,5]. The GHQ was developed as a screening instrument for psychiatric illness and is now often used as an ndicator of psychological well-being $[6,7,8,9]$. The shortened GHQ includes 12 elements: concentration, sleep loss due to worry, perception of role, capability in decision making, whether constantly under strain, perception of problems in overcoming difficulties, enjoyment of day-to-day activities, ability to face problems, loss of confidence, self-worth, general happiness, and whether suffering depression or unhappiness. Responses are given on a 4-point scale ranging from 0 to 3, with 0 being the best score. For our dependent variable we use the Likert scale, which sums the individual components [10]. This gives an overall scale that runs from 0 to 36. To make the interpretation of results more intuitive and consistent with the discussion in sections 3 and 4 , we have re-scaled this measure in order to make it increasing in good health. Therefore we use GHQ' $=36-\mathrm{GHQ}$ rather than the original GHQ score.

Similarly, the Euroqol-5D is a screening instrument of wide use in primary care $[11,12,13,14,15]$. It contains 5 elements or health dimensions: mobility, ability to perform personal care activities, ability to perform daily activities (work, study, family care or leisure activities), pain and anxiety/ depression. Responses are given on a 3 point scale ranging from 1 to 3 , with 1 being the best score. For our dependent variable we add the scores for each of the 5 dimensions according to the set of weights given in Herdman, Badia and Berra [11]. This yield a health index ranging from 1 (best possible state) to 0 . 


\subsection{Measurement and explanation of inequality}

The literature on health inequalities has recently adopted a standard tool for the measurement of income related health inequalities: the concentration index (CI) of health on income [16]. The concentration index has a similar interpretation to the more familiar Gini index for pure health inequality. In fact, the two inequality measures differ in the fact that the ranking variable is income (CI) rather than health (Gini). As the Gini index, the CI ranges between -1 and 1 . A value of -1 would mean that all health is concentrated in the poorest person, whereas a value of 1 would result if all health were concentrated in the richest person. A value of zero would mean that health is equally distributed over income in the sense that the pth percentage of the population ranked by income has exactly the pth percentage of total health for any $p$.

Suppose we are interested in calculating the CI coefficient for a measure of health using individual data in a sample from the population of interest. Let $\mathrm{y}_{\mathrm{i}}$ denote a measure of health

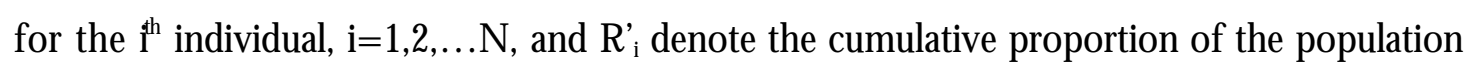
ranked by income up to the $\mathrm{I}^{\text {th }}$ individual (their 'relative income rank').

Ignoring, for expositional purposes, the fact that in general sampling weights will be necessary, the CI of health on income is given by [17],

$$
C=\left(\frac{2}{\bar{y}}\right) \operatorname{cov}\left(y_{i}, R_{i}^{\prime}\right)
$$

where $\bar{y}=E\left(y_{i}\right)$. Now let $\mathrm{y}_{\mathrm{i}}$ be given by the following linear regression model

$$
y_{i}=\beta_{1}+\sum_{k=2}^{K} \beta_{k} x_{k i}+\varepsilon_{i}
$$


where $\mathrm{k}$ is the number of regressors (x). By substituting this for $\mathrm{y}_{\mathrm{i}}$, the CI of $\mathrm{y}$ can be written as [18],

$$
C I=\sum_{k=2}^{K}\left(\beta_{k} \frac{\bar{x}_{k}}{\bar{y}}\right) C^{\prime}{ }_{k}+\left(\frac{2}{\bar{y}}\right) \operatorname{cov}\left(\varepsilon_{i}, R_{i}^{\prime}\right)
$$

The first term in brackets is the elasticity of $\mathrm{y}$ with respect to $\mathrm{x}_{\mathrm{k}}$ evaluated at the sample means $\left(\bar{x}_{k}\right.$ and $\left.\bar{y}\right)$ and $\mathrm{C}_{\mathrm{k}}^{\prime}$ denotes the concentration index of $\mathrm{x}_{\mathrm{k}}$ against income. Thus this inequality measure can be decomposed into an "explained part" and an "unexplained part". The "explained" part can be usefully broken down into the contributions of individual explanatory variables. As for the "unexplained" part, it is a scaled measure of the covariance of the residuals in the regression model with the position of the individual in the distribution of income. As such, the unexplained part should be zero if the regression model contains income as an explanatory variable [19].

If we define the estimated health elasticity with respect to determinant $\mathrm{k}$ as

$$
\hat{\eta}_{k} \equiv \frac{\hat{\beta_{k}} \bar{x}_{k}}{\mu}
$$

then we can rewrite the decomposition in a way such that the CI is just a weighted sum of the inequality in each of its determinants, with the weights equal to the elasticities. That is,

$$
\hat{C} \equiv \sum_{k} \hat{\eta}_{k} \hat{C}_{k}+\left(\frac{2}{\bar{y}}\right) \operatorname{cov}\left(\hat{\varepsilon}_{i}, R_{i}^{\prime}\right)
$$

As mentioned by van Doorslaer and Koolman [20], the decomposition also clarifies how each correlate of health contributes to total income-related health inequality: this contribution is the result of (i) its impact on health, and (ii) how unequally distributed over income it is. 


\subsection{Statistical Inference}

Many of the statistics that we are going to report are non-linear functions of the data whose sampling distributions are hard to obtain. For this reason we shall use bootstrapping methods in order to derive standard errors. The bootstrap estimates for standard errors are computed following the fivestep approach used by van Doorslaer and Koolman [20]. The number of replications has been set to 500 .

\section{Data and variable definitions}

We use the 2002 edition of the Enquesta de Salut de Catalunya [1]. This is a survey representative of the Catalan population (both at the aggregate level and at the "health region level") living in households for the year 2002. We have restricted our analysis to individuals aged $16+$.

The sampling scheme is a complex multi-stage stratified process whereby primary strata are "health regions". Within the latter, municipalities - or city districts in the case of Barcelona(primary sampling units) are selected according to a proportional random sampling scheme. Finally individuals are selected from the primary sampling units using random sampling stratified by age. The information contained in the data files do not allow the identification of all the primary sampling units (because municipalities are not identified), so it is impossible to control for cluster effects. The survey documentation includes weighting factors that correct for the fact that the number of observations within the primary strata is not proportional to actual population. We use these weights in our computations.

The ranking variable is total monthly income earned by the household. Since the ESCAT 2002 does not contain information on income, we have resorted to the Catalan sample in the Spain wide Encuesta Nacional de Salud [21] in order to estimate the joint distribution of household income and some characteristics of the the household (number of women and men adults and number of children) and head of the household (education, activity status and occupation) for the Catalan population. In the Encuesta Nacional de Salud household income is measured as a categorical variable with 6 response categories, so we use an interval 
regression specification for these purposes. The estimates from the latter model allow us to predict the household income for each individual in the ESCAT sample given information on the head of household, and this is subsequently divided by an equivalence factor equal to (number of household members) ${ }^{0.5}$, to adjust for differences in household size.

The initial ESCAT sample included 8400 individuals, but 1332 individuals aged less than 16 were dropped. From the remaining 7068 individuals, 617 were dropped because their household income could not be predicted, 80 because their marital status or their educational attainment was missing and 533 because they had missing values for work characteristics or life styles. A further 261 individuals with missing values in any of the characteristics needed to construct the GHQ index are dropped. Similarly, 33 are dropped when constructing for the Euroqol-5D index. As a result, the estimating samples contain 5577 individuals for G HQ and 5805 individuals for Euroqol-5D.

\section{Empirical results}

\section{1 The joint distribution of health, income and other health covariates in Catalonia}

We model the conditional distributions of GHQ and EQOL-5D as a linear function of socio-economic characteristics. It is useful to stress that this is not a structural model for health and therefore its estimates cannot be given a causal interpretation. However, it might be interpreted as a reduced form static model of demand for health whose estimates provide an indication of how exogenous changes in health determinants can affect the degree of socioeconomic inequality in health. The explanatory variables in this model are the following:

\section{Household income}

The logarithm of equivalent household income. 


\section{Age-gender demographics}

14 age-sex categories corresponding to age groups 16-19, 20-24, 25-29, 30-34, 35-39,4044,45-49,50-54, 55-59, 60-64, 65-69, 70-74, 75-79, 80+ for men and women. The omitted category corresponds to a woman aged between 16 and 19 .

\section{Geographical controls}

17 geographical regions distinguishing between health regions: Tarragona, Tortosa, G irona, Costa Ponent, Barcelones north and Maresme, Centre; and Barcelona city districts: Ciutat Vella, Eixample, Sants-Montjuic, Les Corts, Sarrià-Sant G ervasi, Gràcia, Horta-Guinardó, Nou Barris, Sant Andreu and Sant Marti. The omitted category is the Lleida health region.

\section{Marital Status}

3 marital status categories corresponding to i) single or married ii) divorced or separated and iii) widowed. The omitted category is single or married.

\section{Diet}

A dummy variable that takes the value of one if the individual follows a diet for health reasons and zero otherwise

\section{Type of physical activity during day}

Distinguishing between i) sitting most of the time, ii) standing most of the time iii) walks frequently, iv) daily activities require an important physical effort. The omitted category is sitting most of the time

\section{Exencise}

Distinguishing between i) no physical activity whatsoever or a light activity during more than than 20 minutes per week, ii) a moderate or intense physical activity is done for more than 20 minutes per week. The omitted category is no physical activity whatsoever or a light activity during more than 20 minutes per week 


\section{Smoking habits}

Distinguishing between i) current smoker, ii) ex-smoker and iii) never smoked. The omitted category is current smoker

\section{Drinking habits}

Distinguishing between i) frequent drinker, ii) ceased drinking for health reasons iii) nearly teetotal iv) complete teetotal. The omitted category is frequent drinker.

\section{Risk at work}

An index of risky conditions at work. 0 represents minimu risk and 1 represents maximum risk.

\section{Activity status/ type of contract}

Distinguishing between i) voluntarily out of the labour market (i.e. pensioners, students and family care), ii) civil employee iii) indefinite contract, iv) temporal contract for less than 6 months, v) temporal contract from 6 to 11 months, vi) temporal contracts from 12 to 23 months, vii) temporal contracts for more than 2 years, viii) temporal contracts without time limit, ix) worker from a temporary work company, x) worker without a contract, xi) independent worker, xii) unemployed, xiii) disabled for work. The omitted category is voluntary inactivity (i.e. pensioners, students and family care).

\section{Extra time}

A dummy variable that takes the value of one if the individual does extra time at work and zero otherwise.

\section{Type of working day}

A dummy variable that takes the value of one if the individual does night shifts or irregular time shifts at work and zero otherwise.

\section{Education}

10 educational categories corresponding to i) illiterate ii) basic reading and writing iii) primary school iv) basic secondary school v) bachillerato vi) basic vocational training vii) 
advanced vocational training viii) 3 years university degree ix) 4/5 years university degree $\mathrm{x}$ ) postgraduate. The ommitted category is postgraduate.

\subsubsection{G H O instrument for mental health}

The mean value for the GHQ score for Catalonia is 26.34. However, there is a good deal of variation around this figure depending on the set of covariates. The first column of table 1 presents the parameter estimates for the model of the conditional expectation of the GHQ measure of mental health. Note that the level of household income has a positive and significant value at the $10 \%$. At the mean of the sample, the elasticity of this measure of health with respect to household income is 0.02 . That is, an increase in household income of $10 \%$ is associated to a $0.2 \%$ increase in the G HQ measure of mental health. The age-gender controls show that the GHQ score decreases with age and that women report a smaller score than men all else held equal, although the differences are not significant. There are strong geographical variations too. Lleida is, all else held equal, the region with the highest average score. The Barcelona district with the greatest score is Les Corts, whereas the worst average score in Catalonia, ceteris paribus, is found in the districts of Gràcia and HortaGuinardó. The district of Ciutat-V ella is very similar to Eixample in terms of average GHQ score and fares better than Sarrià-Sant Gervasi, the richest of Barcelona districts. These patterns are worth investigating in detail, for they could throw light on the hypothesis of relative versus absolute income. The marital status indicators show that, all else held equal, widows have the worst GHQ score and that divorcees also fare worse than the single or those who live as a couple. The control for being on a diet for health reasons has the expected sign, although it is not significant. Also as expected, the type of daily activity shows that those who spend most of the day sitting have on average a lower GHQ score than those who stand up, walk or, specially, do activities requiring an important physical effort. Moderate to intense exercise is associated to a greater GHQ score than doing no exercise or doing light exercise. Ex-smokers report a greater GHQ score than current smokers and the difference is not significant between never smokers and current smokers. However, frequent drinkers report a greater GHQ score than teetotalers or near teetotalers and, by a wide margin, those who quit drinking for health reasons. As expected, the estimate for the effect of the risk index shows that the GHQ score is decreasing with perceived risk. The activity 
status controls show that the disabled fare worst in terms of GHQ, that the unemployed do not fare differently from those who do not participate in the labour market because of being in family care, in receipt of a pension or being a student and that individuals with an indefinite contract fare better.. D oing extra time is not significantly associated to a different average GHQ score than not doing extra time but, in contrast, those who work irregular shifts report a significantly smaller score than the rest of individuals. We estimate a positive gradient between educational attainement and reported G HQ. However, the effects are not significant at conventional levels.

\subsubsection{E Q O L -5D instrument for general health}

The estimated average value for the EQOL-5D health instrument is 0.88. Many of the explanatory variables in the specification drive significant variations around this unconditional mean. Household income is positively associated to the score, but not significant at conventional levels. The size of the health elasticity is smaller than that found for mental health, 0.01 . This suggests that income is a more important determinant of mental health than general health in the Catalonian population. The age-gender controls have a similar effect too. The EQOL-5D score decreases rapidly with age and, within most age brackets, women report a lower score. Lleida is again the region where the highest average health score is reported, together with the district of Sant Andreu. The geographical areas with the worst scores, all else held equal, are the district of Horta-Guinardó and Les Corts. Widows report a significantly lower score and divorcees do not report a significantly different score than singles or those living as a couple. The diet for health reasons has the expected sign and significance and, likewise, the daily physical activities controls also show that individuals who report the best score are those that, all else held equal, walk frequently during the day. Those doing moderate or intense exercise fare better than those doing no exercise or light exercise. Surprisingly, non-smokers do not report a significantly different score than current smokers and ex-smokers do not report a greater score than the other two groups. The results for the drinking habits show that those who quit drinking for health reasons have a lower score than the rest of individuals. Teetotalers and near teetotalers are no better than frequent drinkers. The result for the risk index is remarkable. Compared to those for whom the risk is maximum, those who work in a totally risk free environment 
report, on average, a greater EQ OL-5D score, and the difference amounts to $21 \%$ of the mean EQ OL-5D score. As with the mental health score, the disabled report, unsurprisingly, a lower EQ O L-5D score than the voluntary inactive, which in turn are no different than the unemployed. Neither doing extra time nor doing irregular shifts are associated to a different score than the respective default categories. In contrast with the results found for mental health, illiterates, those with basic literacy, those who completed up to primary school, basic secondary school, bachillerato or basic vocational training report a significantly lower level EQ O L-5D score.

\subsection{D ecomposing income related health inequalities in Catalonia}

Which are the factors that generate income related health inequality in Catalonia ? Table 1 provides the answer by showing the contribution of each explanatory variable to the concentration indices. Recall that the contribution of each of the regressors is the product of the elasticity of health and the concentration index of the regressor on income (Table 1 also reports the concentration indices for the latter too)

\subsubsection{GH O instrument for mental health}

Household income is by far the main contributor to income related mental health inequality with a contribution of $102,5 \%$ of the explained concentration index. The age sex structure of the population actually contributes with a reduction of the concentration index. That is, if there were no differences in average mental health by age and gender, the concentration index would be $96 \%$ greater. This reduction is mainly driven by i) the fact that while women between 30 and 64 report on average a lower G HQ score, they are concentrated among high incomes and ii) the fact that while men between 16 and 29 report on average a greater G HQ score, they are concentrated among low incomes and iii) in contrast, men between 30-34 are concentrated in high incomes but report a lower GHQ. Geographical differences also contribute with a reduction to the observed concentration index. In this case, however, the effects are more heterogeneous. There are areas whose population report a lower GHQ and are also concentrated among low incomes. This is clearly the case of the Costa de Ponent, 
Tortosa and Barcelonès nord-Maresme health areas and the Nou Barris district of central Barcelona. These areas contribute with an increase in income related health inequality. On the other hand there are areas whose population report a lower GHQ and are concentrated among high incomes. These are the cases of the districts of Eixample, Sarrià-Sant Gervasi and Gràcia. Overall, the net effect is negative. That is, geographically, Catalans who report low GHQ scores tend to be concentrated in areas with high incomes. The effects of being on a diet and doing moderate or intense exercise both augment the concentration index, but the reasons are different. While those on a diet report a lower GHQ, and tend to be concentrated in low incomes, those doing moderate or intense exercise report a greater GHQ and tend to be concentrated in high incomes. The variation in drinking habits contributes with $7.76 \%$ of the total index. This is driven by the fact that those who have quit drinking for health reasons report a substantially lower G HQ score and are concentrated in low incomes. The contribution of the risk index is positive. While risk decreases reported $\mathrm{GHQ}$, those with less risky conditions tend to be concentrated in high incomes. The activity covariates explain $50 \%$ of the concentration index. That is, if there were no differences in GHQ by activity status, the concentration index would be $50 \%$ smaller. A closer look the individual variables reveals that by far the main contributor is the indefinite contract status. These contracts are concentrated among high incomes and their holders report a greater GHQ score than those who are voluntarily inactive. A similar pattern is found for the civil service status, although the contribution is much smaller. Holders of temporary contracts are concentrated among low incomes, but since they report a greater GHQ score than the voluntarily inactive, these variables contribute with a reduction in the concentration index. The self-employed report a greater GHQ score too, and they are concentrated among high incomes, so this variable contributes positively to the concentration index. Unemployment is concentrated among low incomes and although it is not associated to a smaller GHQ than that reported by the default category, this variable contributes positively to the concentration index. D isability is also concentrated among low incomes and, by contrast, it is associated to a lower GHQ score, so it contributes positively to the concentration index. Variation in the take up of extra time and irregular shifts account for $4.89 \% \%$ and $-7.60 \%$, respectively, of the concentration index. Individuals belonging to either of these categories report a lower GHQ score than the rest of individuals, but while those who do extra time are concentrated among low incomes, those on irregular shifts are concentrated among high incomes. As 
mentioned earlier, the estimates suggest a positive gradient between eduaction and mental health, but we cannot rule out the null hypothesis of no significance for any of the educational dummy parameters. Likewise, the estimated contribution of education to income related inequality in mental health is positive but not significant for all but two educational categories The estimated overall contribution of education is $37.70 \%$, reflecting the fact that lower educational categories are concentrated among low incomes and individuals with a university degree are concentrated among high incomes.

\subsubsection{E $00 \mathrm{~L}-5 \mathrm{D}$ instrument for general health}

Income is also one of the main contributors to the concentration index of the EQOL-5D score on income. The size of the contribution, $30.66 \%$, is much smaller than that observed for mental health, however. By contrast, the contribution of the age-sex structure to the concentration index of the EQOL-5D on income is negative and amounts to $53 \%$. The pattern is similar to what we find in instrumental health: woment between 30-69 report a lower EQOL-5D score and are concentrated in high incomes. As far as the geographical effects are concerned, the population in the Costa de Ponent health region report a lower score than that of Lleida, and at the same time they are concentrated among low incomes, so this contributes positively to the overall concentration index. Nevertheless, the geographical contributions are much smaller than those found for mental health. The effects of being on a diet and moderate or intense exercise are similar to those found for mental health. They contribute positively to the concentration index. Likewise, those who have quit drinking for health reasons both report a lower EQOL-5D score and are concentrated among low incomes. The variation in risky working conditions explains $36.49 \%$ of the concentration index. As with mental health, those in risky environments tend to report a lower EQ OL-5D score and are concentrated among low incomes. The variation in activity status accounts for $40.70 \%$ of the concentration index. Again, as it has been found for mental health, this is driven mainly by the relatively healthier and richer position of those who enjoy an indefinite contract (16\%) or are self employed (8\%) and the relatively less healthy and poorer position of the disabled (14.5\%). The contribution the variation in the educational categories is $40.90 \%$ of the concentration index as the illiterates (16\%) and individuals with basic reading and writing (32\%) report lower EQ OL-5D and are concentrated in low incomes. 


\section{Summary and conclusion}

In this paper we have applied recently developed methodologies [20] to measure and explain the differences in the degree of income related inequality in mental health as measured by the G HQ instrument and general health as measured by the EQ O L-5D instrument. We find that income is the main contributor to inequality, although the share of inequality in mental health that can be explained by income is much greater than the corresponding share of inequality in general health. We also find that the variation in demographic structure reduces income related inequality in mental health and in general health. The regional variations in both instruments for health are striking, with the Barcelona districts faring relatively bad with respect to the rest of geographical areas, Lleida being the health region where, all else held equal, the population reports the greatest level of health. A big share of inequality in the two health measures, but specially mental health, is due to the differences in both health and income of those who enjoy an indefinite contract. We also find that risky working conditions affect both health measures and are able to explain an important share of incomerelated health inequality. We also find that education contributes positively to income related inequality in the two health measures. In the case of mental health, however, the effects are not significant at conventional levels.

The consequences for policy prescriptions are limited in the sense that our estimates cannot be given an unambiguous causal interpretation. Are those who enjoy an indefinite contract healthier because they have job security or have they managed to sign an indefinite contract because they are relatively healthy? Obviously this is hard to ascertain with the data at hand. However, what the data can tell is that job insecurity acts as an indicator for relatively lower health. Moreover, this relationship is present after conditioning on a wide set of potentially confounding variables. It seems then that resources devoted to improve the health of those who do not enjoy job security could be justified not only on the "ability to benefit" principle but, should causality run from good health to job security, on the potential enhancement of job market opportunities too. 


\section{References}

1. DSSS. Enquesta de salut de Catalunya 2002 (Catalan Health Survey 2002). D epartament de Sanitat i Seguretat Social. Generalitat de Catalunya. Barcelona.

2. García Gómez P and López Nicolás A. Regional differences in socio-economic health inequalities in Spain. 2004. Working paper \#757. D epartment of Economics and Business. Universitat Pompeu Fabra

3. Borrell $\mathrm{C}$ and Benach J, editors. Les desigualtats en la salut a Catalunya (Health inequalities in Catalonia). Barcelona: Editorial Mediterrànea, 2003.

4. Goldberg D and Williams P. A user's guide to the General Health Questionnaire. Windsor: Nfer-Nelson, 1988.

5. Bowling A. Measuring health. A review of quality of life measurement scales. Milton Keynes: Open University Press, 1991.

6. Hauk K and Rice N. Health mobility in the UK: a longitudinal analysis of psychological well-being. University of Y ork: mimeo, 2003

7. Weich $\mathrm{S}$, Lewis $\mathrm{G}$ and Jenkins SP. Income inequality and the prevalence of common mental disorders in Britain. British Journal of Psychiatry 2001; 178: 222-227.

8. Wildman J. Income related inequalities in mental health in G reat Britain: analysing the causes of health inequality over time. Journal of Health Economics 2003; 22: 61-87.

9. Jones A and López Nicolás A. Measurement and Explanation of socieconomic inequality in health with longitudinal data. Working Paper \#1. Ecuity III project. Forthcoming Health Economics

10. Likert R.. A technique for the development of attitude scales. Educational and Psychological Measurement 1952; 12: 313-315

11. Herdman M., Badia X. and Berra S. El EuroQ ol-5D: una alternativa sencilla para la medición de la calidad de vida relacionada con la salud en atención primaria. A tención Primaria 2001; 28: 425-429

12. Bosch JL, Hunink MG. Comparison of the Health Utilities Index Mark 3 (HUI3) and the EuroQ ol EQ-5D in patients treated for intermittent claudication. Qual Life Res 2000; 39: 783-790

13. Suárez-Almazor ME, Kendall C, Johnson JA, Skeith K, Vincent D. Use of health status measures in patients with low back pain in clinical settings. Comparison of specific, generic and preference-based instruments. Rheumatology (Oxford) 2000; 39: 783-790

14. Paterson C, Langan CE, McKaig GA et al. Assessing patient outcomes in acute exacerbations of chronic bronchitis: the measure your medical outcome profile (MYMOP), 
medical outcomes study 6item general health survey (MOS6A) and EuroQ ol (EQ-5D). Qual Life Res 2000; 9: 521-527

15. Fransen M, Edmonds J. Reliability and validity of the EuroQol in patients with osteoarthritisof the knee. Rheumatology (Oxford) 1999; 38: 807-813

16. Wagstaff A, Van Doorslaer $E$ and Paci P. Equity in the finance and delivery of health care: some tentative cross-country comparisons. Oxford Review of Economic Policy, 1989; 5, 1: 89-112

17. Van Doorslaer E and Jones A. Inequalities in self-reported health: validation of a new approach to measurement. Journal of Health Economics 2003; 22: 61-87

18. Wagstaff A, van Doorslaer $E$ and Watanabe N. On decomposing the causes of health sector inequalities with an application to malnutrition inequalities in Vietnam. Joumal of Econometrics 2003; 112: 207-223

19. Gravelle $\mathrm{H}$. Measuring income related inequality in health: standardisation and the partial concentration index. Health Economics 2003; 12: 803-819

20. Van Doorslaer E and Koolman X. Explaining the differences in income related health inequalities across E uropean countries. ECuity II Project Working Paper \#6., D epartment of Health Policy and Management, Erasmus University, Rotterdam 2002.

21. CIS. Encuesta Nacional de Salud. Ministerio de Sanidad y Consumo. 2001. Madrid 
Table 1. Health equations: OLS regression coeficients. Means of variables. Concentration indices of dependent and independent variables and health inequality contributions.

\begin{tabular}{|c|c|c|c|c|c|c|c|c|}
\hline & \multicolumn{4}{|c|}{ GHQ } & \multicolumn{4}{|c|}{ EuroQ ol-5D } \\
\hline & Health equation & Mean of Variables & $\mathrm{CI}$ & $\begin{array}{l}\text { Contribution to } \\
\text { health inequality }\end{array}$ & Health equation & Mean of Variables & $\mathrm{CI}$ & $\begin{array}{l}\text { Contribution to } \\
\text { health inequality }\end{array}$ \\
\hline Health index & & 26,3430 & 0,0050 & & & 0,8779 & 0,0080 & \\
\hline Explained health index & & & & 0,0030 & & & & 0,0076 \\
\hline $\begin{array}{c}\text { Log Income } \\
\text { as \% } \\
\end{array}$ & $0,51524^{*}$ & 11,7465 & 0,0134 & $\begin{array}{r}\mathbf{0 , 0 0 3 1} \\
102,50 \% \\
\end{array}$ & 0,01298 & 11,7454 & 0,0134 & $\begin{array}{r}0,0023 \\
30,66 \% \\
\end{array}$ \\
\hline F20-24 & $-0,15377$ & 0,0563 & $-0,2704$ & 0,0001 & $-0,02663$ & 0,0563 & $-0,2729$ & 0,0005 \\
\hline F25-29 & 0,04219 & 0,0535 & $-0,0334$ & 0,0000 & $-0,05183$ & 0,0540 & $-0,0351$ & 0,0001 \\
\hline F30-34 & $-0,68639$ & 0,0345 & 0,2641 & $-0,0002$ & $-0,06670$ & 0,0339 & 0,2671 & $-0,0007$ \\
\hline F35-39 & $-0,78719 *$ & 0,0484 & 0,2571 & $-0,0004$ & $-0,08191$ & 0,0492 & 0,2664 & $-0,0012$ \\
\hline F40-44 & $-0,48134$ & 0,0481 & 0,2145 & $-0,0002$ & $-0,09142$ & 0,0485 & 0,1975 & $-0,0010$ \\
\hline F45-49 & $-0,48762$ & 0,0425 & 0,3512 & $-0,0003$ & $-0,11348$ & 0,0428 & 0,3592 & $-0,0020$ \\
\hline F50-54 & $-0,81050^{*}$ & 0,0429 & 0,2750 & $-0,0004$ & $-0,12081$ & 0,0422 & 0,2759 & $-0,0016$ \\
\hline F55-59 & $-1,46709$ & 0,0369 & 0,2048 & $-0,0004$ & $-0,14951$ & 0,0374 & 0,1832 & $-0,0012$ \\
\hline F60-64 & $-0,42727$ & 0,0241 & 0,1127 & 0,0000 & $-0,18742$ & 0,0241 & 0,1054 & $-0,0005$ \\
\hline F65-69 & 0,19103 & 0,0307 & 0,0361 & 0,0000 & $-0,16489$ & 0,0306 & 0,0337 & $-0,0002$ \\
\hline F70-74 & $-0,51443$ & 0,0254 & $-0,0570$ & 0,0000 & $-0,21489$ & 0,0248 & $-0,0601^{*}$ & 0,0004 \\
\hline F75-79 & $-0,60592$ & 0,0159 & $-0,1247$ & 0,0000 & $-0,24105$ & 0,0158 & $-0,1323$ & 0,0006 \\
\hline F80 & 0,09907 & 0,0127 & $-0,2441$ & 0,0000 & $-0,24307$ & 0,0125 & $-0,2314$ & 0,0008 \\
\hline M16-19 & 0,54237 & 0,0396 & $-0,2037$ & $-0,0002$ & 0,00556 & 0,0392 & $-0,1876$ & 0,0000 \\
\hline M20-24 & 0,72967* & 0,0593 & $-0,2247$ & $-0,0004$ & $-0,00006$ & 0,0587 & $-0,2300$ & 0,0000 \\
\hline M25-29 & 0,36116 & 0,0535 & $-0,0411$ & 0,0000 & $-0,03185$ & 0,0528 & $-0,0437$ & 0,0001 \\
\hline M30-34 & $-0,22752$ & 0,0424 & 0,1376 & $-0,0001$ & $-0,03572$ & 0,0418 & 0,1271 & $-0,0002$ \\
\hline M35-39 & 0,04668 & 0,0430 & 0,0750 & 0,0000 & $-0,05173$ & 0,0425 & 0,0832 & $-0,0002$ \\
\hline M40-44 & 0,31650 & 0,0400 & 0,0667 & 0,0000 & $-0,04723$ & 0,0410 & 0,0727 & $-0,0002$ \\
\hline M45-49 & $-0,26792$ & 0,0378 & 0,1362 & $-0,0001$ & $-0,06556$ & 0,0392 & 0,1320 & $-0,0004$ \\
\hline M50-54 & $-0,17807$ & 0,0319 & 0,0555 & 0,0000 & $-0,06677$ & 0,0322 & 0,0523 & $-0,0001$ \\
\hline M55-59 & 0,07977 & 0,0339 & $-0,0476$ & 0,0000 & $-0,09017$ & 0,0337 & $-0,0360$ & 0,0001 \\
\hline
\end{tabular}




\begin{tabular}{|c|c|c|c|c|c|c|c|c|}
\hline & \multicolumn{4}{|c|}{ GHQ } & \multicolumn{4}{|c|}{ EuroQ ol-5D } \\
\hline & Health equation & Mean of Variables & $\mathrm{CI}$ & $\begin{array}{l}\text { Contribution to } \\
\text { health inequality }\end{array}$ & Health equation & Mean of Variables & $\mathrm{CI}$ & $\begin{array}{l}\text { Contribution to } \\
\text { health inequality }\end{array}$ \\
\hline M60-64 & 0,17627 & 0,0326 & $-0,1592$ & 0,0000 & $-0,07062$ & 0,0329 & $-0,1674$ & 0,0004 \\
\hline M65-69 & 0,72095 & 0,0266 & $-0,3336$ & $-0,0002$ & $-0,10131$ & 0,0262 & $-0,3196$ & 0,0010 \\
\hline M70-74 & 0,63539 & 0,0238 & $-0,3255$ & $-0,0002$ & $-0,04844$ & 0,0241 & $-0,3131$ & 0,0004 \\
\hline M75-79 & 0,71058 & 0,0135 & $-0,4078$ & $-0,0001$ & $-0,11500$ & 0,0136 & $-0,4037$ & 0,0007 \\
\hline $\begin{array}{l}\text { M80 } \\
\text { as \% } \\
\end{array}$ & $-1,11920$ & 0,0100 & $-0,2448$ & $\begin{array}{r}0,0001 \\
-96,72 \% \\
\end{array}$ & $-0,17358$ & 0,0098 & $-0,2351$ & $\begin{array}{c}0,0005^{*} \\
-52,86 \% \\
\end{array}$ \\
\hline Tarragona & $-2,31483$ & 0,0764 & $-0,0398$ & 0,0003* & $-0,01226$ & 0,0748 & $-0,0364$ & 0,0000 \\
\hline Tortosa & $-1,58392$ & 0,0247 & $-0,1610$ & 0,0002 & $-0,02416$ & 0,0239 & $-0,1597$ & 0,0001 \\
\hline Girona & $-2,17904$ & 0,0815 & $-0,0346$ & 0,0002 & $-0,02973$ & 0,0848 & $-0,0398 *$ & 0,0002 \\
\hline Costa Ponent & $-3,24963$ & 0,1883 & $-0,0568$ & 0,0013 & $-0,04014$ & 0,1898 & $-0,0602$ & 0,0005 \\
\hline $\begin{array}{c}\text { Barcelonès nord i } \\
\text { Maresme }\end{array}$ & $-3,45479$ & 0,1123 & $-0,0648$ & 0,0010 & $-0,03720$ & 0,1122 & $-0,0649$ & 0,0003 \\
\hline Centre & $-3,35687$ & 0,2102 & $-0,0097$ & 0,0003 & $-0,05409$ & 0,2072 & $-0,0088$ & 0,0002 \\
\hline Ciutat Vella & $-2,86594$ & 0,0155 & 0,0854 & $-0,0001$ & $-0,05969$ & 0,0149 & 0,0873 & $-0,0001$ \\
\hline Eixample & $-2,58207$ & 0,0408 & 0,3099 & $-0,0012$ & $-0,03883$ & 0,0418 & 0,3253 & $-0,0006$ \\
\hline Sants-Montjuic & $-3,76314$ & 0,0247 & 0,1010 & $-0,0004$ & $-0,04770$ & 0,0281 & 0,1172 & $-0,0003$ \\
\hline Les Corts & $-0,80084$ & 0,0127 & 0,4015 & $-0,0002$ & $-0,07380$ & 0,0128 & 0,3969 & $-0,0004$ \\
\hline Sarrià- Sant G ervasi & $-3,55433$ & 0,0219 & 0,3454 & $-0,0010$ & $-0,04776$ & 0,0214 & 0,3547 & $-0,0004$ \\
\hline Gràcia & $-4,58418$ & 0,0186 & 0,1241 & $-0,0004^{*}$ & $-0,03843$ & 0,0183 & 0,1253 & $-0,0002$ \\
\hline Horta-G uinardó & $-4,74335$ & 0,0310 & 0,0640 & $-0,0004^{*}$ & $-0,08423$ & 0,0304 & 0,0502 & $-0,0001$ \\
\hline Nou Barris & $-3,11281$ & 0,0311 & $-0,0682 *$ & 0,0003* & $-0,03720$ & 0,0303 & $-0,0591$ & 0,0001 \\
\hline Sant Andreu & $-2,47363$ & 0,0253 & 0,1384 & $-0,0003$ & 0,00353 & 0,0239 & 0,1385 & 0,0000 \\
\hline $\begin{array}{c}\text { Sant Martí } \\
\text { as \% } \\
\end{array}$ & $-3,56905$ & 0,0357 & 0,0469 & $\begin{array}{l}-0,0002 \\
-23,56 \% \\
\end{array}$ & $-0,05082$ & 0,0361 & 0,0395 & $\begin{array}{l}-0,0001 \\
-9,82 \% \\
\end{array}$ \\
\hline Widowed & $-1,40757$ & 0,0363 & $-0,0239$ & 0,0000 & $-0,02706 *$ & 0,0355 & $-0,0134$ & 0,0000 \\
\hline Divorced / Separated & $-0,59694 *$ & 0,0226 & 0,1823 & $-0,0001$ & $-0,00013$ & 0,0222 & 0,1790 & 0,0000 \\
\hline as $\%$ & & & & $-1,56 \%$ & & & & $0,19 \%$ \\
\hline Diet & $-0,23295$ & 0,1480 & $-0,0121$ & 0,0000 & $-0,03520$ & 0,1485 & $-0,0199$ & 0,0001 \\
\hline
\end{tabular}




\begin{tabular}{|c|c|c|c|c|c|c|c|c|}
\hline & \multicolumn{4}{|c|}{ GHQ } & \multicolumn{4}{|c|}{ EuroQ ol-5D } \\
\hline & Health equation & Mean of Variables & $\mathrm{CI}$ & $\begin{array}{l}\text { Contribution to } \\
\text { health inequality }\end{array}$ & Health equation & Mean of Variables & $\mathrm{CI}$ & $\begin{array}{l}\text { Contribution to } \\
\text { health inequality }\end{array}$ \\
\hline as $\%$ & & & & $0,53 \%$ & & & & $1,56 \%$ \\
\hline Standing most of the time & 0,38036 & 0,1944 & 0,0084 & 0,0000 & 0,02100 & 0,1939 & 0,0078 & 0,0000 \\
\hline Walks frequently & 0,51738 & 0,4234 & 0,0141 & 0,0001 & 0,04422 & 0,4239 & 0,0130 & 0,0003 \\
\hline $\begin{array}{l}\text { Physical effort on daily } \\
\text { activities }\end{array}$ & 1,06207 & 0,1019 & $-0,0640$ & $-0,0003^{*}$ & 0,03642 & 0,1008 & $-0,0560$ & $-0,0002$ \\
\hline as \% & & & & $-4,08 \%$ & & & & $1,04 \%$ \\
\hline $\begin{array}{l}\text { Moderate or intense } \\
\text { physical activity }\end{array}$ & 0,36851 & 0,2738 & 0,0567 & $0,0002^{*}$ & 0,01902 & 0,2721 & 0,0530 & 0,0003 \\
\hline as $\%$ & & & & $7,24 \%$ & & & & $4,11 \%$ \\
\hline Never smoked & 0,20267 & 0,4891 & 0,0054 & 0,0000 & 0,00395 & 0,4875 & 0,0042 & 0,0000 \\
\hline $\begin{array}{l}\text { Ex-smoker } \\
\text { as \% }\end{array}$ & 0,55985 & 0,1784 & 0,0005 & $\begin{array}{l}0,0000 \\
0,74 \%\end{array}$ & 0,01037 & 0,1817 & $-0,0022$ & $\begin{array}{l}0,0000 \\
0,06 \%\end{array}$ \\
\hline $\begin{array}{l}\text { Ceased drinking for health } \\
\text { reasons }\end{array}$ & $-1,38263$ & 0,0175 & $-0,2541$ & 0,0002 & $-0,08897$ & 0,0178 & $-0,2596$ & 0,0005 \\
\hline Nearly teetotal & $-0,33426$ & 0,4245 & 0,0038 & 0,0000 & $-0,00314$ & 0,4276 & 0,0050 & 0,0000 \\
\hline $\begin{array}{c}\text { Complete teetotal } \\
\text { as } \%\end{array}$ & $-0,10037$ & 0,2790 & $-0,0187$ & $\begin{array}{l}0,0000 \\
7,76 \%\end{array}$ & 0,00175 & 0,2771 & $-0,0220^{*}$ & $\begin{array}{l}0,0000 \\
5,89 \%\end{array}$ \\
\hline $\begin{array}{l}\text { Risk } \\
\text { as \% } \\
\end{array}$ & $-1,62226$ & 0,2570 & $-0,0474$ & $\begin{array}{r}\mathbf{0 , 0 0 0 8} \\
25,01 \% \\
\end{array}$ & $-0,19887$ & 0,2577 & $-0,0475$ & $\begin{array}{r}\mathbf{0 , 0 0 2 8} \\
36,49 \% \\
\end{array}$ \\
\hline Civil employee & 0,18610 & 0,0261 & 0,5112 & 0,0001 & 0,01266 & 0,0258 & 0,4879 & 0,0002 \\
\hline Indefinite contract & 0,59025 & 0,2935 & 0,1528 & 0,0010 & 0,02294 & 0,2933 & 0,1597 & 0,0012 \\
\hline $\begin{array}{c}\text { Temporal contract }<6 \\
\text { months }\end{array}$ & 0,56711* & 0,0350 & $-0,2438$ & $-0,0002$ & 0,01518 & 0,0356 & $-0,2647$ & $-0,0002$ \\
\hline $\begin{array}{l}\text { Temporal contract 6-11 } \\
\text { months }\end{array}$ & 0,73755 & 0,0343 & $-0,2008$ & $-0,0002$ & 0,01312 & 0,0339 & $-0,1920$ & $-0,0001$ \\
\hline $\begin{array}{c}\text { Temporal contract } 12-23 \\
\text { months }\end{array}$ & 0,35742 & 0,0080 & 0,0169 & 0,0000 & 0,03820 & 0,0085 & $-0,0100$ & 0,0000 \\
\hline $\begin{array}{c}\text { Temporal contract }>2 \\
\text { years }\end{array}$ & 1,05381 & 0,0034 & $-0,2635^{*}$ & 0,0000 & 0,01360 & 0,0035 & $-0,1937$ & 0,0000 \\
\hline Temporal contract & $-0,23120$ & 0,0207 & $-0,1441$ & 0,0000 & 0,01644 & 0,0201 & $-0,1505$ & $-0,0001$ \\
\hline
\end{tabular}




\begin{tabular}{|c|c|c|c|c|c|c|c|c|}
\hline & \multicolumn{4}{|c|}{ GHQ } & \multicolumn{4}{|c|}{ EuroQ ol-5D } \\
\hline & Health equation & Mean of Variables & $\mathrm{CI}$ & $\begin{array}{l}\text { Contribution to } \\
\text { health inequality }\end{array}$ & Health equation & Mean of Variables & $\mathrm{CI}$ & $\begin{array}{l}\text { Contribution to } \\
\text { health inequality }\end{array}$ \\
\hline \multicolumn{9}{|l|}{ without limit } \\
\hline $\begin{array}{l}\text { Worker from a temporary } \\
\text { work company }\end{array}$ & 4,15159 & 0,0013 & $-0,3833^{*}$ & $-0,0001 *$ & 0,09104 & 0,0014 & $-0,3928$ & $-0,0001$ \\
\hline Without a contract & $-0,69803$ & 0,0115 & $-0,0219$ & 0,0000 & $-0,02074$ & 0,0118 & $-0,0227$ & 0,0000 \\
\hline Independent worker & 0,39454 & 0,0848 & 0,0958 & 0,0001 & 0,02667 & 0,0851 & 0,0928 & 0,0006 \\
\hline Unemployed & $-0,25455$ & 0,0670 & $-0,2344$ & 0,0002 & $-0,01057$ & 0,0678 & $-0,2345$ & $-0,0002$ \\
\hline D isabled for work & $-2,71001$ & 0,0195 & $-0,2943$ & 0,0006 & $-0,22989$ & 0,0201 & $-0,3112$ & 0,0011 \\
\hline as $\%$ & & & & $50,21 \%$ & & & & $40,70 \%$ \\
\hline Extra time & $-0,12139$ & 0,6362 & $-0,0501$ & 0,0001 & $-0,00555$ & 0,6354 & $-0,0517$ & 0,0002 \\
\hline as $\%$ & & & & $4,89 \%$ & & & & $2,73 \%$ \\
\hline Irregular working day & $-0,59368$ & 0,0909 & 0,1113 & $-0,0002$ & $-0,00891$ & 0,0911 & 0,1119 & $-0,0001$ \\
\hline as $\%$ & & & & $-7,60 \%$ & & & & $1,36 \%$ \\
\hline Illiterate & $-1,29080$ & 0,0160 & $-0,4599$ & $0,0004^{*}$ & $-0,1418$ & 0,0159 & $-0,4589$ & 0,0012 \\
\hline Basic Reading and writing & $-0,23527$ & 0,1157 & $-0,2308$ & 0,0002 & $-0,0788$ & 0,1162 & $-0,2340$ & 0,0024 \\
\hline Primary school & $-0,23758$ & 0,2466 & $-0,0477$ & 0,0001 & $-0,0329$ & 0,2461 & $-0,0474$ & 0,0004 \\
\hline Basic secondary school & 0,15122 & 0,2032 & $-0,0771$ & $-0,0001$ & $-0,0305$ & 0,2022 & $-0,0725$ & 0,0005 \\
\hline Bachillerato & 0,15651 & 0,1368 & 0,1277 & 0,0001 & $-0,0312$ & 0,1363 & 0,1231 & $-0,0006$ \\
\hline \multirow{2}{*}{$\begin{array}{c}\text { Basic vocational training } \\
\text { Advanced vocational } \\
\text { training }\end{array}$} & $-0,03442$ & 0,0756 & $-0,0167$ & 0,0000 & $-0,0298^{*}$ & 0,0755 & $-0,0037$ & 0,0000 \\
\hline & 0,48827 & 0,0728 & $-0,0444^{*}$ & $-0,0001$ & $-0,0218$ & 0,0736 & $-0,0484$ & 0,0001 \\
\hline \multirow{3}{*}{$\begin{array}{c}3 \text { years university degree } \\
4 / 5 \text { years university } \\
\text { degree } \\
\text { as } \%\end{array}$} & 0,42077 & 0,0523 & 0,2718 & 0,0002 & $-0,0234$ & 0,0527 & 0,2714 & $-0,0004$ \\
\hline & 0,2182906 & 0,0721 & 0,4079 & $0,0002 *$ & $-0,0173$ & 0,0725 & 0,4009 & $-0,0006$ \\
\hline & & & & $37,70 \%$ & & & & $40,90 \%$ \\
\hline Adjusted R-squared & 0,1139 & & & & 0,28958 & & & \\
\hline
\end{tabular}

